\title{
EPISTEMOLOGIA E GÊNERO: UM ESTUDO DAS PUBLICAÇÕES NO GRUPO DE TRABALHO 1 DO ENANCIB
}

\author{
EPISTEMOLOGY AND GENDER: A STUDY OF THE \\ PUBLICATIONS OF THE WORKING GROUP 1 OF \\ ENANCIB
}

\author{
Fernando Cruz Lopesa \\ Mariana Rodrigues Gomes de Mello ${ }^{b}$ \\ Jonathas Luiz Carvalho Silvac \\ Daniel Martínez-Ávilad \\ Oswaldo Francisco de Almeida Juniore
}

\begin{abstract}
RESUMO
Objetivo: abordar as produções sobre gênero e suas correlações com o campo da Ciência da informação no Encontro Nacional de Pesquisa em Ciência da Informação (ENANCIB) no contexto do grupo de trabalho 1 (GT1). Metodologia: realizou-se revisão da literatura em obras de autores e filósofos que tratam das temáticas, bem como do corpus levantado nos anais do ENANCIB no intervalo de 10 anos, compreendido entre os anos de 2010 e 2019. Resultados: pensar a questão epistemológica da Cl pelo viés dos estudos de gênero é o fazer científico como práxis, ou seja, organizar possibilidades da discussão com a produção de conteúdo em si. Conclusão: sugere-se novos estudos que evidenciem aspectos históricos-epistemológicos voltados às questões de gênero e teorias que conversem com ela, a fim de que a $\mathrm{Cl}$ possa fomentar melhor a percepção do outro, a construção de uma mentalidade menos preconceituosa, a diminuição da exclusão, ou seja, a desconstrução da Cl como uma ciência neoliberal é necessária para dar visibilidade a todos os grupos dela excluídos em seus primórdios.
\end{abstract}

a Doutorando pelo Programa de pós-graduação em Ciência da Informação pela Universidade Estadual Paulista (UNESP). Analista Sociocultural - Bibliotecário na Secretaria de Educação do Estado de São Paulo. E-mail: lopes.fred@gmail.com.

b Doutoranda no Programa de pós-graduação em Ciência da Informação pela Universidade Estadual Paulista (UNESP). E-mail: mariana.rg.mello@unesp.br.

c Doutor em Ciência da Informação pela Universidade Federal da Bahia (UFBA). Docente do curso de Biblioteconomia e do Programa de Pós-Graduação em Biblioteconomia da Universidade Federal do Cariri (UFCA). E-mail: jonathas.carvalho@ufca.edu.br

d Doutor em Documentação pela Universidad Carlos III de Madrid (UC3M). Docente do Departamento de Biblioteconomía y Documentación da Universidad Complutense de Madrid (UCM) e docente do Programa de Pós-graduação em Ciência da Informação da Universidade Estadual Paulista (UNESP). E-mail: martinez.avila@unesp.br

e Doutor em Ciências da Comunicação pela Universidade de São Paulo (USP). Docente do Programa de Pós-graduação em Ciência da Informação na Universidade Estadual Paulista (UNESP). E-mail: ofaj@ofaj.com.br 
Descritores: Epistemologia. Gênero. ENANCIB. Teoria Crítica.

\section{INTRODUÇÃO}

A concepção do que a Ciência da Informação (Cl) é, atualmente, depende essencialmente de construções históricas e epistemológicas que a área obteve até o momento. As pessoas envolvidas e suas manifestações políticas e culturais são fundamentais para a construção da área de forma que quase torna-se um truísmo o entendimento de que a $\mathrm{Cl}$, como qualquer outra Ciência, é produto de seu tempo e espaço. Porém, se torna necessário nos debruçarmos sobre as práticas histórico-epistemológicas que afetam a construção da ciência para compreender os motivos pelos quais alguns assuntos são pouco discutidos ou sequer mencionados, principalmente quando os estudos se referem à questões relacionadas com grupos excluídos da área.

Um dos temas pouco lembrados é a discussão sobre a temática dos estudos de gênero, uma vez que poucos ou insuficientes estudos se relacionam com essa discussão na $\mathrm{Cl}$. Isso pode ser observado no artigo $A$ questão do gênero na literatura em Ciência da Informação, de Bufrem e Nascimento (2012), que analisou 40 anos de produção científica da área e encontrou apenas 74 artigos com esse tema. Contudo, esse número seria menor considerando apenas a temática histórico-epistemológica, pois a pesquisa compreendeu a $\mathrm{Cl}$ como um todo.

As autoras do artigo ainda discutem a diferença entre a quantidade de artigos sobre o tema e a quantidade de mulheres que estão presentes na área. É possível, então, salientar a pouca participação de mulheres na história da área, possibilitando o questionamento: A Cl sofre do efeito Matilda?

O sociólogo Robert Merton identificou uma situação em que, na posteridade, cientistas mais conhecidos receberam os méritos por descobertas de cientistas menos conhecidos. Essa situação foi nomeada de Efeito Matthew (MERTON, 1968). A historiadora da ciência Margaret Rossiter, por sua vez, cunhou o Efeito Matilda, referente às mulheres pesquisadoras que não recebem o devido reconhecimento, que acaba sendo dedicado apenas aos homens envolvidos. O próprio Merton serve como exemplo, já que não deu os devidos 
créditos em suas pesquisas aos materiais produzidos por sua assistente Harriet Zuckerman, que se tornou sua esposa, mas não sua coautora (BURKE, 2012).

Segundo Paul B. Preciado (2014, p. 31), “[...] A arquitetura do corpo é política." Sendo assim, entende-se que a relação sexo/gênero é fundamentada em percepções espaço-temporais que anulam a mulher e sua capacidade, dada a cultura falocêntrica. Audre Lorde (2019), coloca como é culturalmente aceito que grupos oprimidos tenham a árdua tarefa de superar a distância entre a realidade da opressão e a consciência do opressor.

Partindo do seguinte problema: Como a ideia de gênero é abordada nas produções de artigos no Encontro Nacional de Pesquisa em Ciência da Informação (ENANCIB) no âmbito do Grupo de Trabalho 1 (GT1)? Este artigo tem como escopo principal abordar as produções sobre gênero e suas correlações com o campo da Ciência da informação no ENANCIB no contexto do GT1. A pesquisa justifica-se pela necessidade de verificarmos como a questão de gênero vem sido epistemologicamente contemplada no GT1 do ENANCIB, ante a importância e visibilidade do evento e das teorias sociais e filosóficas que perpassam o tema e servem como alicerce às reflexões na Ciência da Informação no seu percurso histórico. A escolha pelo GT1 foi devido a percepção de que a temática era pouco desenvolvida no grupo e por isso se torna necessário entender porquê o GT responsável pela discussão epistemológica não produzia tantos trabalhos que poderiam estar atrelados a essa discussão. A eleição do ENANCIB foi em face da grande relevância do evento para a Cl brasileira, sendo ele o principal evento de pesquisa na Ciência da Informação do Brasil, portanto, com os trabalhos mais relevantes produzidos nacionalmente.

Porém, para tanto, é necessário a compreensão da ordem interna que constitui um dado domínio, suas teorias e seus discursos, sem desconsiderar o aspecto histórico-social e institucional que envolve cada microesfera do poder presente nas instituições que modelam o pensar social e exclui o sujeito que se opõe a seguir irrefletidamente a massa. Sobrepor o corriqueiro, propor novas investigações e dar oportunidades para elas, derrubando mitos e preconceitos são alguns dos papéis dos pesquisadores da Cl. Contudo, tudo isso passa por 
questões sociais, como as de gênero e histórico-epistemológicas, como as teorias críticas. Daí a importância de estudos na $\mathrm{Cl}$ que envolvam também questões teóricas.

\section{REFLEXÕES SOBRE O SURGIMENTO DA CI}

Segundo Maria Nélida González de Gómez (2000), a Cl surge em um momento de mudanças na escala de produção do conhecimento que culminou no encarecimento do tratamento, operacionalização, transmissão e, consequentemente, nos usos e aproveitamento desses grandes estoques de registro do conhecimento.

O surgimento do termo Ciência da Informação está diretamente ligado ao contexto do pós-guerra quando em 1958, o químico e documentalista Jason Farradane em cisão com os bibliotecários da Library Association da GrãBretanha, criou o Institute of Information Scientists (ISS) (PINHEIRO, 2013).

Para Pinheiro (2013), o papel de Jason Farradane é essencial para a criação do primeiro curso de $\mathrm{Cl}$ no mundo, instituído em 1961 na City University de Londres com o nome de Collecting and Communicating Scientific Knowledge.

Farradane pensava as atividades de informação fortemente relacionadas ao conhecimento científico, daí a sua preocupação com uma sólida e de alto nível formação dos profissionais de informação. Por sua iniciativa foi lançado, em 1959, o Bulletin of The Institute of Information Scientists, movido pela sua percepção da necessidade de comunicar e informar. (PINHEIRO, 2013, p. [13]).

A Cl não foi considerada de imediato como uma nova Ciência; tinha-se o entendimento de que era um suporte para outras disciplinas científicas, como Cibernética, Psicologia, Ciências Cognitivas e Linguística. Talvez pelo fato de o criador ser químico e de que muitos eventos foram produzidos com foco na comunicação científica na área (PINHEIRO, 2013), deu-se a impressão de que a $\mathrm{Cl}$ era mais uma disciplina dentro das áreas.

Farradane, em defesa da Ciência da Informação, afirma primeiramente que a principal característica da área é da "[...] natureza do pensamento e sua expressão e comunicação [...] determinando e adaptando as comunicações às 
necessidades ou à maneira de pensar das pessoas" (1980 apud ROBREDO, 2003, p. 60).

Contudo, se a localização do surgimento do termo é simples, o seu conceito não é tão simples assim, pois não se tratou de um evento isolado na Grã-Bretanha, como se pôde observar. A construção do entendimento do que viria a ser a Ciência da Informação aconteceu ao longo do século XIX até sua criação no século XX.

Assim, é fundamental entender o espaço da $\mathrm{Cl}$ em um período histórico onde os Estados Unidos e a União das Repúblicas Socialistas Soviéticas (URSS) estavam em uma guerra política e ideológica e cada movimento significava um novo investimento, ocasionando progresso no histórico da Cl. Burke (2012) afirma que após o lançamento do foguete Sputnik pelo Programa espacial soviético, os Estados Unidos investiram 170 bilhões de dólares em seu Programa espacial. No Quadro 1 se apresentam de forma cronológica alguns eventos históricos da Ciência da Informação que aconteceram de forma significativa desde o período do fim da Segunda Guerra Mundial até pleno período da Guerra Fria. O ano 1962 foi um momento históricos chave das tensões entre os blocos imperialistas e comunistas com a Crise dos mísseis de Cuba que, nos Estados Unidos, também teve repercussões para a necessidade de informação e comunicação com fins belicistas.

\section{Quadro 1 - Alguns eventos significativos nos primórdios da Ciência da Informação}

\begin{tabular}{|l|l|l|}
\hline \multicolumn{1}{|c|}{ EVENTO } & ANO & \multicolumn{1}{|c|}{ PAÍS } \\
\hline Publicação do artigo de Vannevar Bush intitulado As we may think & 1945 & Estados Unidos \\
\hline Conferência de Informação Científica da Royal Society. & 1948 & Grã-Bretanha \\
\hline $\begin{array}{l}\text { A Organização das Nações Unidas para Educação, Ciência e Cultura } \\
\text { (UNESCO) promove duas Conferências sobre Biblioteconomia e } \\
\text { Documentação. }\end{array}$ & 1950 & França \\
\hline Publicação do American Documentation. & 1950 & Estados Unidos \\
\hline Publicação do Nauchno-Tekhnicheskaya Informatsyia. & 1950 & URSS \\
\hline $\begin{array}{l}\text { Publicação do artigo de Suzanne Briet intitulado Qu'est-ce que la } \\
\text { documentation? }\end{array}$ & 1951 & França \\
\hline Criação do Instituto Estatal de Informação Científica e Técnica (em & 1952 & URSS \\
\hline
\end{tabular}


Fernando Cruz Lopes, Mariana Rodrigues Gomes de Mello, Jonathas Luiz Carvalho Silva, Daniel Martínez-Ávila, Oswaldo Francisco de Almeida Junior

\begin{tabular}{|c|c|c|}
\hline $\begin{array}{l}\text { russo Vserossiisky Institut Nauchnoi i Tekhnicheskoi Informatsii - } \\
\text { VINITI). }\end{array}$ & & \\
\hline Publicação do Referativnyi Zhurnal (VINITI Abstracts Journal). & 1952 & URSS \\
\hline Criação do Classification Research Group & 1952 & Grã-Bretanha \\
\hline $\begin{array}{l}\text { Criação do Comitê para Treinamento de Documentalistas (TD) da } \\
\text { Federação Internacional de Informação e Documentação (FID). }\end{array}$ & 1953 & Bélgica \\
\hline Lançamento do Sputnik. & 1957 & URSS \\
\hline $\begin{array}{l}\text { Conferência Internacional de Informação Científica organizada pela } \\
\text { Academia Nacional de Ciências. }\end{array}$ & 1958 & Estados Unidos \\
\hline Criação do Institute of Information Scientists (ISS). & 1958 & Grã-Bretanha \\
\hline $\begin{array}{l}\text { Publicação de artigo de Mikhailov sobre "finalidades e problemas da } \\
\text { informação científica". }\end{array}$ & 1959 & URSS \\
\hline Criação do Bulletin of The Institute of Information Scientists. & 1959 & Grã-Bretanha \\
\hline $\begin{array}{l}\text { Reformulação do FID/TD e nova denominação Comitê para Educação e } \\
\text { Treinamento (FID/ET). }\end{array}$ & 1959 & Bélgica \\
\hline Criação do curso Collecting and Communicating Scientific Knowledge. & 1961 & Grã-Bretanha \\
\hline $\begin{array}{l}\text { Conferência de Especialistas em Ciência da Informação no Georgia } \\
\text { Institute of Technology. }\end{array}$ & 1962 & Estados Unidos \\
\hline
\end{tabular}

Fonte: Adaptado de Freire, 2002

Nota-se que as políticas de segurança do pós-guerra, alinhadas com a intensificação da relação entre a Ciência, o Estado e a economia industrial, direcionou economicamente a informação. Nesse sentido, a Cl serviu como base para a corrida científica entre os países que queriam demonstrar seu poder na Guerra Fria. Para González de Gómez (2000), esse cenário é necessário para compreender o viés industrial e a mercantilização da informação que iniciou um processo de índice econômico apenas pela posse da informação.

\section{EPISTEMOLOGIA DA CIÊNCIA DA INFORMAÇÃO}

$\mathrm{O}$ pequeno exercício de construção histórica do surgimento da $\mathrm{Cl}$ também é um exercício técnico-científico do ofício e, portanto, um compromisso político para compreender como assuntos ora poucos discutidos, como gênero, também fazem parte da construção epistemológica da área (LE GOFF, 2013). 
Dentro desse exercício, pode-se aceitar o desafio proposto por Marc Bloch (2001, p. 65) ao afirmar que: "[...] A incompreensão do presente nasce fatalmente da ignorância do passado, mas é talvez igualmente inútil esgotar-se a compreender o passado, se nada se souber do presente". Entende-se que o surgimento da $\mathrm{Cl}$ é um processo histórico de ruptura com os paradigmas do pensamento científico da modernidade. Para Silva (2017) o paradigma tende a estabelecer um êxito do discurso técnico-científico, pois consegue delimitar as práticas da área. Ressalta-se que as mais diferentes práticas científicas que se fazem presentes na $\mathrm{Cl}$, alinham-se com a tecnologia, organização, comunicação e mediação desses fazeres.

Os primeiros teóricos da $\mathrm{Cl}$ comumente a definem por esse olhar do fazer técnico científico:

[...] é uma ciência voltada para o estudo da produção, organização, armazenamento, disseminação e uso da informação. Nesse sentido, entendem a Cl como uma disciplina voltada para os processos envolvidos com a informação processos normalmente entendidos como processos técnicos, aplicados, de intervenção. O conceito de informação que sobressai de tais definições é a idéia de informação como uma "coisa", um ente da realidade dotado de objetividade (ARAÚJO, 2009, p. 200).

Entender essa concepção de $\mathrm{Cl}$ foi fundamental para compreendê-la como uma ciência desde seus primórdios. No entanto, não se provou ser entendida apenas por esse paradigma ao longo do tempo. Para Kuhn (2006, p. 13), o entendimento de paradigmas, é que são "[...] realizações científicas universalmente reconhecidas que, durante algum tempo, fornecem problemas e soluções modelares para uma comunidade de praticantes de uma ciência."

Desde o início da área já se era sabido que apesar do nome, seu objeto de estudo não era a informação, mas sim os fazeres envolvidos pela informação. Eles são quem definem o paradigma físico da Cl indicado por Capurro (2003). Para Rendón Rojas (2012, p. [4]), a complexidade e, portanto, o surgimento de diferentes paradigmas na área está intrinsecamente relacionado ao fato:

[...] de que o mundo informativo-documentário não é um fenômeno natural existente independentemente do ser humano. Ao contrário, é um mundo construído em sua totalidade pela atividade do ser humano em geral, quanto ao que definimos a pessoa como "ser informacional". O anterior significa que para 
existir, isto é, desenvolver seu ser, os indivíduos necessitam criar, consumir, transformar, transmitir, conservar informação. Essa necessidade existencial e por consequência ontológica, determina a aparição do mundo informativo-documentário, junto com seus objetos; [...] sujeitos; e processos.

Da mesma forma, Silva (2017, p. 53) lista alguns motivos pelos quais a informação, por si só, não deve ser entendida como o objeto da área. Entre esses motivos, estão:

[...] pelo fato de que a informação só ganha sentido a partir das relações sociais e no processo de mediação e apropriação de sentidos, o que confirma o seu aparato construtivo (ou sócio construtivo); [...] pelo fato de que a informação na $\mathrm{Cl}$ está eminentemente ligada a práticas investigativas e operacionais relativas a diversas temáticas e linhas de pesquisa que promovem sustentação teórico-epistemológica a área. [...]

Logo, a compreensão da construção do contexto histórico-social, e das relações mediadoras e dos conflitos que emanam dele é imprescindível para entendermos as relações histórico-epistemológicas que norteiam o domínio do conhecimento que pretendemos pesquisar. Sendo assim:

[...] o objeto de estudo deve considerar a construção histórica de uma determinada área do conhecimento valorizando suas identidades ameaçadas e modificadas, pois são os conflitos que movem as transformações de qual fenômeno, seja científico, seja do conhecimento em geral. (SILVA, 2017, p. 53).

Dessa forma, revisitar o panorama histórico inicial da área é fundamental para entender a construção de seu objeto e dos paradigmas desenvolvidos nesse pouco mais de meio século que a área existe. Essencialmente, é necessário entender também que a $\mathrm{Cl}$ é poli-epistemológica (GONZÁLEZ DE GÓMEZ, 2000), uma vez que a área pode ser observada através de estratos distintos e analisada conforme essas especificidades. Além disso, a área se formou com escolas, concepções sobre o que é informação, documentos e seus fazeres técnicos e científicos. Para Rendón Rojas (2012, p. [7]) essa multiplicidade de entendimentos acerca da área "[...] é induzida por uma realidade objetiva. Se essa realidade é respeitada, então essa visão não é inventada, ainda que tampouco possa pretender ser a única e verdadeira." 
Para González de Gómez (2000, p. 4) o caráter poli-epistemológico da área está atrelado aos estratos de entendimento da "informação", que ela chama de "ação da informação" e que podem ser três:

[...] semântico-discursiva, enquanto a informação responde às condições daquilo sobre o que informa, estabelecendo relações com um universo prático-discursivo ao qual remetem sua semântica ou conteúdos; outra, meta-informacional, onde se estabelecem as regras de sua interpretação e de distribuição, especificando o contexto em que uma informação tem sentido; a terceira, uma dimensão infra-estrutural, reunindo tudo aquilo que como mediação disponibiliza e deixa disponível um valor ou conteúdo de informação, através de sua inscrição, tratamento, armazenagem e transmissão.

Entender essas ações da informação é poder rascunhar os paradigmas da área. Essa interpretação proposta por González de Gómez (2000) compreende aspectos sociais e cognitivos que surgem na discussão semântica e da linguagem que estão vinculadas aos fazeres histórico-culturais de seus agentes e aspectos tecnológicos do estrato da infra-estrutura que vai discutir de forma mais abrangente, contextos e formas de operacionalizar os suportes e métodos da tecnologia. Sendo assim, fica perceptível os três principais paradigmas da $\mathrm{Cl}$ : o paradigma físico, o paradigma cognitivo e o paradigma social.

Não que a fragmentação tenha sido um processo fácil para a área, contudo, ao menos, foi possível que a $\mathrm{Cl}$ se propusesse a discutir dentro dos três paradigmas acima. Pode-se observar que a consolidação da área vai permitindo o aprofundamento das discussões nos paradigmas e mudanças na relação da $\mathrm{Cl}$ com seu objeto.

Nas décadas de 1960 e 1970, tem-se o paradigma físico com maior preponderância nas discussões da área. Nesse paradigma, a discussão foi em torno da Teoria Matemática da Comunicação de Shannon e influenciou estudos sobre organização e recuperação da informação. As discussões aqui foram feitas principalmente sob duas abordagens: documentalista (informação para ciência e tecnologia) e matemática (informação sobre a ciência e tecnologia) (FERNANDES, 2018).

Concomitantemente, os estudos cognitivos estavam sendo discutidos por pensadores como o Simpósio de Teoria da Informação que aconteceu no 
Massachusetts Institute of Technology em 1956. Durante a década de 1960, os estudos sobre a compreensão do conhecimento humano, das máquinas e a interação entre os dois, produziu os principais autores e atores (BARRETO, 2008). Nos anos 1980 , os estudos cognitivos na $\mathrm{Cl}$ ganharam força com nomes, como: Bertran Brookes, Nicholas Belkin, Peter Ingwersen, Brenda Dervin, Gernot Wersig, entre outros.

No paradigma cognitivo "A característica da informação passou a ser sua '(in)tensão' para gerar o conhecimento no indivíduo e consequentemente em sua realidade" (BARRETO, 2008, p. [9]). Nesse paradigma o conhecimento é uma construção interpretativa dos sujeitos. As abordagens deste paradigma se instrumentalizam do conhecimento como um dos lados da tríade: informaçãodados-conhecimento (ARAÚJO, 2014).

Assim como os outros dois paradigmas, o social também é construído ao longo dos anos na história da $\mathrm{Cl}$. Um dos primeiros fatores que pode ser observado na influência do paradigma social são os estudos da Escola de Chicago, na década de 1930 e 1940, assim como a Epistemologia social de Margaret Egan e Jesse Shera, na década de 1950; a questão racial com a Black Librarianship, no final da década de 1970 e as questões de gênero propostas por Hope Olson nos anos 1990 (MELO; TARGINO, 2019).

Como um marco no paradigma social tem se, em 1991, o I CoLIS International Conference on Conceptions of Library and Information Science em Tampere na Finlândia. No evento os trabalhos apresentados estavam conectados com uma visão marcada pelo fato de:

[...] que esse "algo" identificado como "informação", obtido no processo de interação entre dados e conhecimento, não era definido apenas pelo sujeito específico, um sujeito individual, isolado, destacado do mundo e do convívio com outros. Antes, os contextos específicos (as realidades históricas, políticas, econômicas, culturais) são parcialmente determinantes do processo. Ao mesmo tempo, o coletivo, isto é, as demais pessoas com quem o sujeito específico interage, também são fundamentais na determinação do processo - ninguém conhece sozinho, necessidades e usos de informação são coletivamente formados. (ARAÚJO, 2014, p. 17).

O paradigma social é uma ruptura muito recente com os outros paradigmas da $\mathrm{Cl}$, com um entendimento do objeto que destoa do proposto pelo 
paradigma físico e cognitivo. O entendimento social precisa de consolidação e propostas metodológicas para a área (SILVA, 2017).

No paradigma social podem ser trabalhadas as abordagens construcionista, hermenêutica, pragmática e fenomenológica, sendo a Teoria Crítica um suporte potencial do entendimento de informação, que segundo essa teoria, é entendida:

[...] como recurso fundamental para a condição humana no mundo e, como tal, a primeira percepção que se tem é de sua desigual distribuição entre os atores sociais. Como recurso, a informação é apropriada por alguns, que garantem para si o acesso. Aos demais, sobra a realidade da exclusão. [...] temáticas estudadas no âmbito dessa teoria envolvem a questão da democratização da informação, do acesso à informação por parte de grupos e classes excluídos e marginalizados, a criação de formas e sistemas alternativos de informação, [...] estudos que denunciam a dimensão ideológica dos equipamentos culturais [...] reproduzindo lógicas sociais de dominação e aprofundando diferenças cognitivas e de sensibilidade, são conduzidas por pesquisadores que aliam o estudo da informação a uma sociologia crítica da cultura. (ARAÚJO, 2009, p. 197).

A estreita relação da Ciência da Informação com as práticas sociais sempre esteve presente em sua história. Em seu início buscou, a princípio, a fuga da realidade cartesiana.

\section{AS GERAÇÕES DAS TEORIAS CRÍTICAS E SEUS FUNDAMENTOS}

A Teoria Crítica começou a ser idealizada em 1924, no Instituto de Pesquisas Sociais da Universidade de Frankfurt na Alemanha, um departamento de teoria social e filosófica (COTRIM; FERNANDES, 2013). Ela se contrapõe à teoria clássica cartesiana, reducionista, mecanicista, acrítica, que percebe o objeto, tal como se apresenta fenomenologicamente, ante o olhar distante do observador, que analisa o fenômeno tal como se apresenta, sem emitir um parecer crítico. E, consequentemente, também ao positivismo que se inspira em muitos aspectos no cartesianismo. São expoentes da primeira geração da Escola de Frankfurt nomes, tais como, Adorno, Horkheimer e Marcuse (MELLO; MARTÍNEZ-ÁVILA; ARAÚJO; VALENTIM, 2020). 
Adorno e Horkheimer (1985) defendem que a real racionalidade se manifesta pela reflexão crítica e autônoma e não pelo domínio da técnica. $O$ conhecimento genuíno é decorrente da racionalidade crítica, emancipatória e não da compreensão da ciência enquanto técnica, ou da simples repetição de conceitos e preceitos de forma heterônoma e irreflexiva. Adorno e Horkheimer (1985) separam a razão em duas espécies opostas: a subjetiva, também conhecida como razão instrumental ou técnica, e a objetiva, denominada emancipatória. A primeira está profundamente imbricada à tecnocracia na sociedade capitalista, cujo objetivo é o lucro. Não há a ideia de finalismo na razão subjetiva, isto é, um propósito axiológico e autoconsciente (MELLO; MARTíNEZÁVILA; ARAÚJO; VALENTIM, 2020). "A técnica é a essência desse saber, que não visa conceitos e imagens, nem o prazer do discernimento, mas o método, a utilização do trabalho de outros, o capital" (ADORNO; HORKHEIMER, 1985, p. 18).

No entanto, na acepção de Habermas, maior expoente da segunda geração dos frankfurtianos, a crítica severa ao conceito de razão da primeira geração da Escola de Frankfurt, aliada à exaltação do materialismo histórico, conduziria ao irracionalismo. Adorno e Horkheimer compreendiam que a razão emancipatória não seria possível com o desenvolvimento do sistema capitalista, pois ele ofusca a consciência da classe proletária. Contudo, no entendimento de Habermas (1981), este posicionamento tem que ser analisado com cautela, à medida que o projeto da modernidade ainda está em curso, não se findou. Para tanto, Habermas argumenta que ainda há a possibilidade da racionalização do mundo pela via emancipatória. Ele defende que para a retomada do projeto emancipatório é necessário transpor a teoria marxista em alguns pontos cruciais "[...] por exemplo, a centralidade do trabalho e a identificação do proletário como agente da transformação social" (COTRIM; FERNANDES, 2013, p. 316). Para isso, esse filósofo idealiza uma nova concepção de razão, mais dialógica, decorrente da intersubjetividade do debate democrático. Razão que é fruto do que Habermas entende como ação comunicativa.

Posteriormente, as teorias críticas, também conhecidas como póscríticas, apresentam o que se chama de descentramento, o que implica que a 
noção de classe marxista, dual (patrões e empregados) muito usada pela primeira fase da Escola de Frankfurt, foi redirecionada mais ao sujeito com suas identidades e subjetividades.

Nas teorias críticas de origem pós-estruturalistas (FOUCAULT, 1979; DERRIDA, 1995; DELEUZE, 2000); pós-colonialista (FANON, 1979; BHABHA, 1994; SAID, 2011); teoria queer (BUTLER, 1993; MISKOLCI, 2012; PELÚCIO, 2012); multiculturalista (MCLAREN, 2000; HALL, 2020) não há um "pano de fundo", como na teoria tradicional cartesiana que é impulsionada pelo positivismo, ou na primeira geração da teoria crítica marcada pelo marxismo. Essas novas teorias críticas são fundamentadas por correntes que se alinham, no entanto, possuem peculiaridades. Por isso o debate se volta aos movimentos mais específicos, como o feminismo, a diversidade de gênero, a racial e a cultural. A discussão ainda perpassa pela opressão capitalista que opera com radicalismo do neoliberalismo na nossa sociedade, trazendo consequências tanto econômicas quanto sociais segregatórias.

Porém, as teorias críticas estão mais preocupadas com a relação de poder e do discurso do sujeito oprimido, numa perspectiva mais singularizada. Discussão que nasce na pós-modernidade, que em linhas gerais, é uma era de rupturas, individualismo e incertezas. Marcada pelos paradigmas e ideologias instituídos que são colocados em xeque ante ao convívio entre diversas escolas de pensamentos, instabilidade axiológica em todos os campos e vulnerabilidade. Não existem mais verdades absolutas e nem condições de se enxergar tal possibilidade ante a ausência de garantias em todas as esferas (MELLO, 2020).

A corrente majoritária alega que a pós-modernidade surge por volta da década de 1950, fruto de mudanças de natureza artística e científica, bem como na forma de reflexão da sociedade em geral (SANTOS, 1986). Tem-se conferido duas fases diversas ao período: a primeira inaugura-se em 1950 e termina na Guerra Fria - momento em que vigora o grande alcance da mídia analógica. Já a segunda etapa inicia-se com o término da Guerra Fria, tendo como marco a disseminação da informação por meio da mídia digital, perdurando até os dias hodiernos. Momento que se inter-relaciona com a instituição da $\mathrm{Cl}$, como visto. 
Apesar, de como já dito na introdução, focar-se mais na busca das questões de gênero que envolvam reflexões histórico-epistemológicas, importantes fundamentos teóricos aos muitos domínios, do qual a $\mathrm{Cl}$ faz parte, importante explanar brevemente o que trata cada um dos movimentos que dá ensejo às teorias críticas pós-modernas, a fim de compreender o contexto geral dessas teorias que foram movidas por movimentos sociais fundamentais na construção de qualquer domínio social aplicado.

As teorias pós-estruturalistas (FOUCAULT, 1979; 2012; DERRIDA, 1995; DELEUZE, 2000) defendem a desconstrução de textos e teorias estruturados com conteúdo objetivo, conceitos e categorias fixas. Isto porque compreendem que eles não respondem mais à sociedade do novo milênio, o que há são discursos relativos ao contexto histórico-social, fruto de uma pluralidade de sentidos.

Nesse sentido, Foucault (2012) expõe que o discurso não é uma cópia fiel da realidade. É uma representação culturalmente construída, à medida que as práticas de poder circulam pela sociedade ligadas ao contexto histórico. Pela desconstrução histórica de sistemas ou regimes formadores de opinião, pode-se verificar o significado e alcance de um discurso, analisando os motivos pelos quais certas categorias, linhas de pensamento e argumentos tomam um caráter de mais verdadeiros do que outros. Ante este cenário, o próprio discurso posiciona o sujeito e define seu papel frente a prática discursiva.

Já o pós-colonialismo (FANON, 1979; BHABHA, 1994; SAID, 2011) incide na discussão que tenta explicar as consequências histórico-econômicas e sociais de tantos anos de exploração das metrópoles às suas colônias e as implicações disso no mundo estruturados por aldeias e não mais por territórios colonizados, exaltando os atuais movimentos migratórios.

No que tange a teoria queer (BUTLER, 1993; MISKOLCI, 2012; PELÚCIO, 2012) ela discute identidade de gênero e poder, ampliando as discussões feministas ao movimento $L G B T Q I+$, recusando a categorização universais do sujeito em heterossexual, homossexual, homem ou mulher, à medida que compreendem uma enorme gama de desdobramentos que não se sobrepõem uns aos outros por um aspecto natural. Tudo passa por uma relação de poder 
que é socialmente construída, pois não é essencial. Isto implica que pra teoria queer todas as identidades sociais são anômalas.

Quanto ao multiculturalismo (MCLAREN, 2000; HALL, 2020) ele trata da identidade pós-moderna e as muitas espécies de cultura que se desdobram em: cultura de massa, cultura popular e cultura erudita em formas mais amplas em sociedades miscigenadas e, portanto, com uma gama cultural. O homem moderno tinha uma identidade cultural e social bem definidas, sólidas, o que não ocorre com as fronteiras móveis pós-modernas, o que pode ocasionar uma crise de identidade no sujeito. Ademais, a diversidade cultural e étnica é vista por muitos como uma ameaça para a identidade da nação.

\section{ASPECTOS METODOLÓGICOS}

No que tange aos procedimentos metodológicos, este estudo é de natureza exploratória. Segundo Gil (2008), a pesquisa exploratória desvenda intuições, aperfeiçoa ideias e altera conceitos. Para tanto, realizou-se uma revisão da literatura em obras de autores e filósofos que tratam das temáticas, bem como do corpus levantado nos anais do ENANCIB no intervalo de 10 anos, compreendido entre os anos de 2010 e 2019. A coleta dos trabalhos apresentados aconteceu no mês de novembro de 2020. Os descritores utilizados foram: "mulher", "gênero", "feminis" e "sexualidade" com o intuito de aumentar a probabilidade de encontrar mais trabalhos usando também os termos que são complementares ao gênero. Foram considerados todos os tipos de trabalhos apresentados permitidos pelo evento.

\section{LEVANTAMENTO DOS DADOS}

Entre os anos que compreendem a pesquisa, apenas no ano de 2019 o GT1 apresentou produção sobre a temática abordada. Assim, entre os anos de 2010 e 2018 não foi apresentado nenhum trabalho sobre essa questão. Importante ressaltar que a última vez que o assunto foi tratado pelo GT1 foi no ano de 2008 e apenas 11 anos depois ele reapareceu (NASCIMENTO; 
OLIVEIRA, 2019). No Gráfico 1 se apresentam as frequências de trabalhos sobre gênero publicados por ano no GT1 do ENANCIB.

\section{Gráfico 1 - Trabalhos apresentados no ENANCIB e no GT1 sobre gênero}

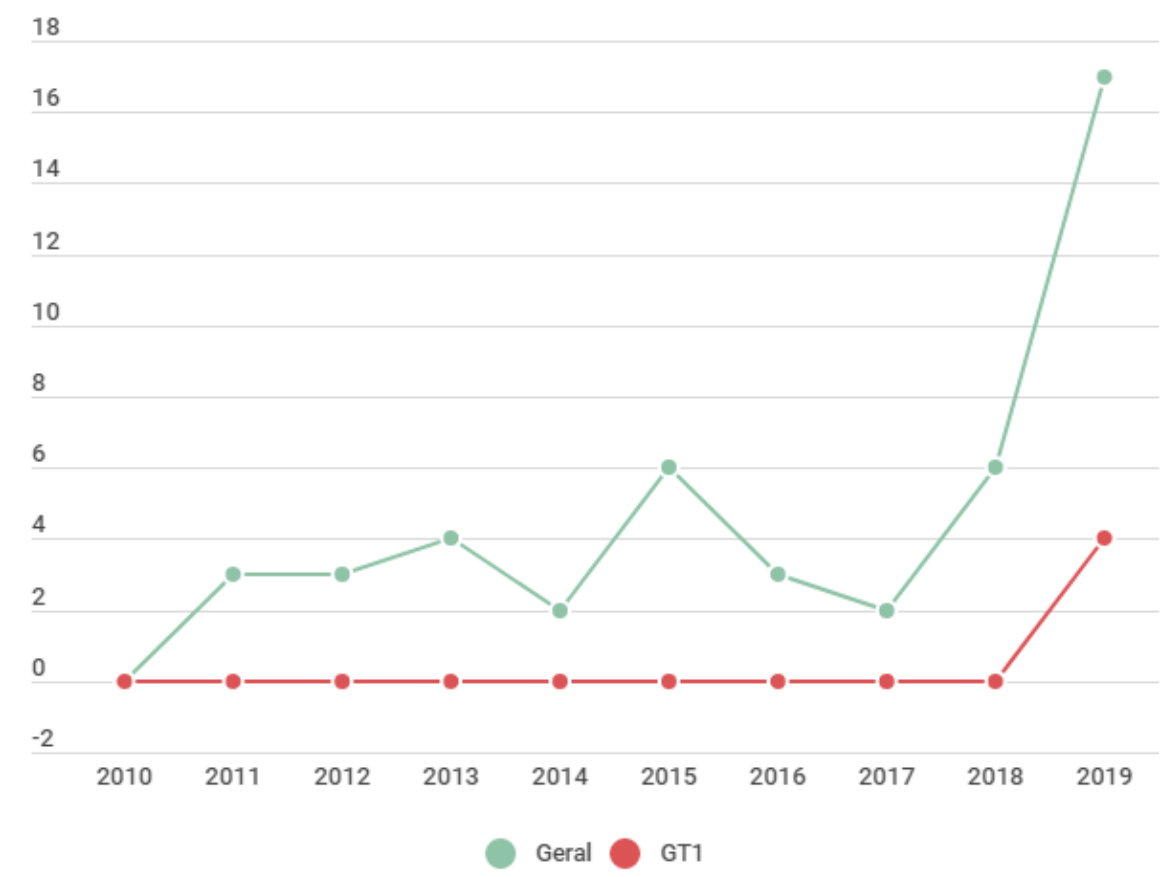

Fonte: Adaptado de Nascimento e Oliveira (2019)

Ao todo, são quatro trabalhos encontrados com essa temática, sendo que três são da modalidade Trabalho completo e um é da modalidade Resumo expandido. O trabalho Mulher e gênero na produção científica da Ciência da Informação de Nascimento e Oliveira (2019) trata da abordagem de discussões sobre gênero na produção brasileira no nível da pós-graduação e do ENANCIB. A pesquisa coletou dados produzidos no período compreendido entre 2007 a 2018.

Outro artigo foi Estudos sobre mulheres na Ciência da Informação de Xavier e Kobashi (2019). A pesquisa versa sobre a produção científica brasileira abrangendo periódicos que estão disponibilizados em três repositórios: Base de Dados Referenciais de Artigos de Periódicos em Ciência da Informação (BRAPCI), Base do Encontro nacional de pesquisa em Ciência da Informação (BENANCIB) e Scientific Electronic Library Online (SciELO).

O último trabalho completo apresentado é $A$ bibliografia do esquecimento: por que silenciamos a produção literária de Carolina Maria de Jesus? de Santos, 
Silva e Lubisco (2019). Diferentemente dos outros trabalhos, esse não apresenta uma discussão voltada para a produção científica da $\mathrm{Cl}$ diretamente, e sim para a bibliografia como fonte de informação e como uma disciplina.

$\mathrm{Na}$ categoria resumo expandido, o trabalho A Ciência da Informação pela perspectiva feminista de Rodrigues e Francelin (2019) aborda o feminismo como uma possibilidade de construção epistemológica da $\mathrm{Cl}$ e argumenta que a Epistemologia Social de Margaret Egan e Jesse Shera serve de porta de entrada para o feminismo desde um ponto de vista epistemológico.

\section{ANÁLISE DOS DADOS}

Pensar a questão epistemológica da $\mathrm{Cl}$ pelo viés dos estudos de gênero é o fazer científico como práxis, ou seja, organizar possibilidades da discussão com a produção de conteúdo em si. Propor uma possibilidade epistemológica de conversão entre estudos de gênero e $\mathrm{Cl}$ faz com que fortaleça a área. Abordar temáticas fora da fronteira estabelecida, repensar os métodos e metodologias e analisar o objeto por outros vieses, garante a epistemologia como uma prática que não se esgota em si.

Marc Bloch (2001), ao relacionar o ato de pensar acerca dos métodos científicos e dos limites da discussão temática reflete que a ciência que se isola, se limita a "um fragmento do universal movimento rumo ao conhecimento" ( $p$. 50). Entretanto, para Bloch uma forma de validação epistemológica é a associação ao conjunto das tendências científicas de outras disciplinas, sendo que esse exercício diferenciaria o trabalho técnico do trabalho filosófico.

Essa linha tênue entre o fazer técnico e o filosófico é o que permite a profundidade da discussão epistemológica e consequente importância de determinados assuntos. Não tanto como um revisionismo, mas como uma meaculpa da área. Por exemplo, sabe-se, com afirmações de Jesse Shera, que Margaret Egan não recebeu tantos créditos pela formulação da teoria da Epistemologia Social (FURNER, 2004; MORÁN, 2014), sendo o próprio caso de Efeito Matilda da $\mathrm{Cl}$. Há também Suzanne Briet e sua discussão sobre documentação que apenas foi retomada no começo dos anos 2000 
(SALDANHA, 2012). Duas breves situações de como a questão do gênero pode ter afetado a $\mathrm{Cl}$.

A defesa pela discussão de assuntos que tragam à tona a questão da liberdade individual e defesa da diversidade de vozes e discursos é de extrema importância para a consolidação e diversificação das propostas da área. Novas interpretações, teorias, construções epistemológicas surgem da diversidade de vivências.

A agenda neoliberal não permite a multiplicidade das vivências. É fundamental compreender como o diverso é tratado por essa compreensão de mundo, e todos os indivíduos entendidos como minorias estão ameaçados. Audre Lorde, faz uma colocação cirúrgica sobre como a luta tem que ser de todos.

[...] Como negra, lésbica, socialista, mãe de dois, entre eles um menino, e integrante de um casal inter-racial, com frequência me vejo parte de um grupo em que a maioria me define como desviante, difícil, inferior ou simplesmente 'errada'.

Com a minha presença em todos esses grupos, aprendi que a opressão e a intolerância com a diferença podem se manifestar em todas as formas, cores e sexualidades; e que, entre aqueles com quem compartilhamos os objetivos de libertação e de um futuro possível para nossos filhos, não podem existir hierarquias de opressão. Aprendi que o machismo (uma crença na superioridade inerente de um sexo sobre todos os outros e, portanto, seu direito à dominância) e o heterossexismo (uma crença na superioridade inerente de uma forma de amar sobre todas as outras e, portanto, seu direito à dominância) emergem ambos da mesma fonte que o racismo - uma crença na superioridade inerente de uma raça sobre todas as outras e, portanto, seu direito à dominância. (2020, p. 63) .

Neste artigo, o debate é sobre a discussão de gênero na epistemologia, mas não é possível fazê-la se não considerar-se a questão hegemônica como um dos principais fatores que reduz a mulher e sua representação na comunidade científica. Para Butler (2019), essa preocupação com o outro se faz necessária, pois normalmente a preocupação é a construção da inteligibilidade do sujeito: "Quem sou?"; "O que sou?"; e "Quem posso me tornar?", mas que essas perguntas apenas condicionam a possibilidade de seu devir e não constituem a verdade de seu si-mesmo. 
Em contrapartida, quando se pergunta para o outro "Quem é você?", parte-se para uma linha de raciocínio de responsabilidade moral. Assim, entende-se que:

[...] diante de nós existe um outro que não conhecemos e não podemos apreender totalmente, alguém cujas unicidade e não substitutibilidade impõem um limite ao modelo de reconhecimento recíproco oferecido no esquema hegeliano e, em termos mais gerais, à possibilidade de conhecer o outro. (BUTLER, 2019, p. 45).

Portanto, é visível que se trata de uma área que historicamente sempre teve mais mulheres que homens, produzindo uma história pautada no direito à dominância, como salienta Lorde (2020). Que fica visível pelo esquecimento das teorias propostas pelas pesquisadoras, da pesquisa de Bufrem e Nascimento (2012) e os poucos trabalhos recuperados em 40 anos de $\mathrm{Cl}$, pelos 10 anos de GT1 do ENANCIB com apenas quatro (4) trabalhos sobre a temática. O machismo na ciência é um projeto político.

Talvez, pela proximidade dessas discussões, pode-se pensar que 0 Paradigma Social é o campo com maiores possibilidades de entrelaçamento entre a $\mathrm{Cl}$ e as discussões de gênero. Para Silva (2017), os fundamentos sociais da informação sempre estiveram presentes na discussão da $\mathrm{Cl}$, portanto, perpassando por todos os paradigmas, mas que podem ser notados quando observados pelo agrupamento: epistemologia social (década de 1950); responsabilidade social (década de 1970) e a formação do paradigma social da Cl (década de 1990).

\section{Quadro 2 - Paradigmas da Ciência da Informação e aproximações temáticas}

\begin{tabular}{|l|l|l|l|}
\hline & Paradigma físico & $\begin{array}{l}\text { Paradigma } \\
\text { cognitivo }\end{array}$ & Paradigma social \\
\hline Enfoques & $\begin{array}{l}\text { Sistema de informação } \\
\text { e processos } \\
\text { tecnológicos no âmbito } \\
\text { da organização e } \\
\text { tratamento da } \\
\text { informação } \\
\text { desenvolvido por } \\
\text { mulheres e/ou sobre } \\
\text { mulheres. }\end{array}$ & $\begin{array}{l}\text { Usuário e processos } \\
\text { psicológicos para } \\
\text { organização, } \\
\text { tratamento e serviços } \\
\text { de informação } \\
\text { desenvolvido por } \\
\text { mulheres e/ou sobre } \\
\text { mulheres. }\end{array}$ & $\begin{array}{l}\text { Domínio e processos } \\
\text { sociais na construção } \\
\text { coletiva, interacionista e } \\
\text { dialógica da } \\
\text { informação desenvolvido } \\
\text { por mulheres e/ou sobre } \\
\text { mulheres. }\end{array}$ \\
\hline
\end{tabular}




\begin{tabular}{|c|c|c|c|}
\hline $\begin{array}{l}\text { Assuntos } \\
\text { que } \\
\text { englobam os } \\
\text { estudos de } \\
\text { paradigmas }\end{array}$ & $\begin{array}{l}\text { Estudo de usuários com } \\
\text { foco nas questões de } \\
\text { gênero. } \\
\text { - } \\
\text { abordagem quantitativa } \\
\text { Recuperação da } \\
\text { informação } \\
\text { de/sobre/para mulheres. } \\
\text { - } \\
\text { enfoque técnico no } \\
\text { sistema de informação } \\
\text { Estudos sobre } \\
\text { organização e } \\
\text { representação da } \\
\text { informação sob o } \\
\text { enfoque técnico } \\
\text { de/sobre/para mulheres. }\end{array}$ & $\begin{array}{l}\text { Estudo de usuários com } \\
\text { foco nas questões de } \\
\text { gênero. } \\
\text { - } \\
\text { abordagem qualitativa } \\
\text { Recuperação da } \\
\text { informação } \\
\text { de/sobre/para mulheres. } \\
\text { - } \\
\text { enfoque na função do } \\
\text { sistema para o usuário } \\
\text { da informação a partir do } \\
\text { uso de paradigmas como } \\
\text { behaviorista, } \\
\text { processamento da } \\
\text { informação e } \\
\text { funcionalista-estrutural. } \\
\text { Estudos sobre } \\
\text { organização e } \\
\text { representação da } \\
\text { informação } \\
\text { de/sobre/para mulheres. }\end{array}$ & $\begin{array}{l}\text { Estudo de usuários com } \\
\text { foco nas questões de } \\
\text { gênero. } \\
- \\
\text { enfoque na construção } \\
\text { coletiva, crítica e } \\
\text { interacionista entre } \\
\text { usuário e centro de } \\
\text { informação com foco em } \\
\text { mulheres. } \\
\text { Estudos aproximativos } \\
\text { entre o desenvolvimento } \\
\text { tecnológico e social na } \\
\text { construção da } \\
\text { informação sobre/para } \\
\text { mulheres. } \\
\text { A concepção } \\
\text { sociointeracionista } \\
\text { da informação, } \\
\text { especialmente a partir } \\
\text { da elaboração dos } \\
\text { processos de mediação } \\
\text { e serviços de } \\
\text { informação } \\
\text { de/sobre/para mulheres. }\end{array}$ \\
\hline
\end{tabular}

Fonte: Adaptado de Silva, 2017

Ressalta-se que o Quadro 2 é uma exemplificação das possibilidades da discussão de gênero na $\mathrm{Cl}$. Para além disso, a função primordial dessa pesquisa é entender que a área precisa dar voz a qualquer grupo que sofra marginalização, assim como pontua Audre Lorde:

[...] Não posso me dar ao luxo de acreditar que estar livre da intolerância é somente direito de um grupo específico. Tampouco posso me dar ao luxo de escolher as frentes nas quais devo lutar contra essas forças da discriminação onde quer que elas apareçam para me destruir, não demorará muito que apareçam para destruir vocês. (LORDE, 2020, p. 65).

Pois, vê-se uma crescente onda de conservadorismo e tradicionalismo e o foco dessas correntes ideológicas é a destruição das liberdades individuais e diversidade. 


\section{CONSIDERAÇÕES FINAIS}

O objetivo proposto neste estudo foi alcançado, uma vez que foi possível mensurar como a questão gênero vem sendo tratada pela $\mathrm{Cl}$, fundamentados na sua trajetória histórico-epistemológica, bem como na coleta e análise dos dados, a partir dos trabalhos relacionados à temática, levantados nos anais do ENANCIB no intervalo dos últimos 10 anos.

A partir disso, não se pode deixar de notar que muitos espaços precisam ser reconhecidos e preenchidos por mulheres que escreveram sobre epistemologia da $\mathrm{Cl}$, mas que foram relegadas ao ostracismo. Não é necessário tirar mais esqueletos do armário, mas o caso de Audre Lorde, sempre apresentada como intelectual negra, lésbica, poeta e professora, poucas vezes é apresentada como bibliotecária. Seus estudos, embora versem muitas vezes sobre raça, feminismo e poesia, complementam a discussão da $\mathrm{Cl}$ de maneira fenomenológica. Trata-se de uma pensadora que precisa ser incorporada às discussões epistemológicas da $\mathrm{Cl}$.

Com base nos achados da pesquisa, sugere-se novos estudos que evidenciem aspectos históricos-epistemológicos voltados às questões de gênero e teorias que conversem com ela, a fim de que a $\mathrm{Cl}$, possa fomentar melhor a percepção do outro, a construção de uma mentalidade menos preconceituosa, a diminuição da exclusão, ou seja, a desconstrução da $\mathrm{Cl}$ como uma ciência neoliberal é necessária para dar visibilidade a todos os grupos dela excluídos em seus primórdios.

\section{REFERÊNCIAS}

ADORNO, Theodor Wiesengrund; HORKHEIMER, Max. Dialética do esclarecimento. Rio de Janeiro: Zahar, 1985.

ARAÚJJO. Carlos Alberto de Ávila. Correntes teóricas da Ciência da Informação. Ciência da Informação, Brasília, v. 38, n. 3, p. 192-204, set./dez. 2009. Disponível em: http://revista.ibict.br/ciinf/index.php/ciinf/article/view/1719/1347. Acesso em: 17 nov. 2020. 
ARAÚJO. Carlos Alberto de Ávila. O que é Ciência da Informação? Informação \& Informação, Londrina, v. 19, n. 1, p. 01-30, jan./abr. 2014. Disponível em: http://www.uel.br/revistas/uel/index.php/informacao/article/view/15958/14205. Acesso em: 25 nov. 2020.

BARRETO, Aldo Albuquerque. Uma quase história da Ciência da Informação. DataGramaZero, v. 9, n. 2, 2008. Disponível em:

http://hdl.handle.net/20.500.11959/brapci/6633. Acesso em: 24 nov. 2020.

BHABHA, Homi. The location of culture. Nova York: Routledge, 1994.

BLOCH, Marc. Apologia da História, ou, o ofício do historiador. Rio de Janeiro: Jorge Zahar Ed., 2001. 159 p.

BUFREM, Leilah Santiago; NASCIMENTO, Bruna Silva. A questão do gênero na literatura em ciência da informação. Em Questão, Porto Alegre, v. 18, n. 3, p. 199-214, 2012. Disponível em:

http://hdl.handle.net/20.500.11959/brapci/11473. Acesso em: 06 dez. 2020.

BURKE, Peter. Uma História social do conhecimento II: da Enciclopédia à Wikipédia. Rio de Janeiro: Zahar, 2012.

BUTLER, Judith. Bodies that matter: on the discursive limits of sex. New York: Routledge, 1993.

BUTLER, Judith. Relatar a si mesmo: crítica da violência ética. Belo Horizonte: Autêntica Editora, 2019. 198 p.

CAPURRO, Rafael. Epistemologia e Ciência da Informação. In: ENCONTRO NACIONAL DE PESQUISA E PÓS-GRADUAÇÃO EM CIÊNCIA DA INFORMAÇÃO (ENANCIB), 5., 2003, Belo Horizonte. Anais [...]. Belo Horizonte: UFMG, ANCIB, 2003. p. 1-21. Disponível em:

http://www.capurro.de/enancib_p.htm. Acesso em: 12 dez. 2020.

COTRIM, Gilberto; FERNANDES, Mirna. Fundamentos de Filosofia. São Paulo: Saraiva, 2013.

DELEUZE, Gilles. Diferença e repetição. São Paulo: Relógio D’água, 2000.

DERRIDA, Jacques. A Escritura e a Diferença. 2. ed. Trad. Maria Beatriz Marques Nizza da Silva. São Paulo: Perspectiva S.A, 1995.

FANON, Franz. Os Condenados da Terra. Rio de Janeiro: Civilização Brasileira, 1979.

FERNANDES, Geni Chaves. Desempacotando o paradigma físico da Ciência da Informação. Logeion: Filosofia da Informação, Rio de Janeiro, v. 4, n. 2, p. 127-146, mar. 2018. Disponível em:

http://revista.ibict.br/fiinf/article/view/4216. Acesso em: 24 nov. 2020. 
FOUCAULT, Michel. A arqueologia do saber. 8. ed. Rio de Janeiro: Forense Universitária, 2012.

FOUCAULT, Michel. Microfísica do poder. Organização e tradução de Roberto Machado. Rio de Janeiro: Edições Graal, 1979.

FREIRE, Isa Maria. Da construção do conhecimento científico à responsabilidade social da Ciência da Informação. Informação \& Sociedade: Estudos, João Pessoa, v. 12, n. 1, 2002. Disponível em: https://ridi.ibict.br/handle/123456789/194. Acesso em: 19 nov. 2020.

FURNER, Jonathan. "A Brilliant Mind": Margaret Egan and Social Epistemology. Library Trends, Urbana-Champaign, v. 52, n. 4, p. 792-809, 2004. Disponível em: https://www.ideals.illinois.edu/handle/2142/1698. Acesso em: 06 dez. 2020.

GIL, Antonio Carlos. Métodos e técnicas de pesquisa social. São Paulo: Atlas, 2008.

GONZÁLEZ DE GÓMEZ, Maria Nélida. Metodologia da pesquisa no campo da Ciência da Informação. DataGramaZero, Rio de Janeiro, v. 1, n. 6, dez. 2000. Disponível em:

https://ridi.ibict.br/bitstream/123456789/127/1/GomesDataGramaZero2000.pdf. Acesso em: 18 nov. 2020.

HABERMAS, Jürgen. Modernity versus postmodernity. New German Critique, n. 22, p. 3-14, 1981.

HALL, Stuart. A identidade cultural na pós-modernidade. São Paulo: Lamparina, 2020.

KUHN, Thomas. A estrutura das revoluções científicas. São Paulo: Perspectiva, 2006.

LE GOFF, Jacques. História e memória. 7. ed. Campinas: Editora da Unicamp, 2013. 504 p.

LORDE, Audre. Irmã outsider. Belo Horizonte: Autêntica, 2019. 237 p.

LORDE, Audre. Sou sua irmã. São Paulo: Ubu Editora, 2020. 224 p.

MCLAREN, Peter. Multiculturalismo crítico. São Paulo: Cortez, 2000.

MELO, Mayte Luanna Dias de; TARGINO, Maria das Graças. In: ENCONTRO NACIONAL DE PESQUISA E PÓS-GRADUAÇÃO EM CIẾNCIA DA INFORMAÇÃO (ENANCIB), 20., 2019, Florianópolis. Anais [...]. Florianópolis: UFSC, UDESC, ANCIB, 2019. Disponível em: https://conferencias.ufsc.br/index.php/enancib/2019/paper/view/527/513. Acesso em: 25 nov. 2020. 
MELLO, Mariana Rodrigues Gomes de; MARTÍNEZ-ÁVILA, Daniel; ARAÚJO, Leda Maria; VALENTIM, Marta Lígia Pomim. Entre técnica e reflexão: um estudo da função social das bibliotecas públicas a partir da teoria crítica. Informação \& Informação, Londrina, v. 25, n. 4, p. 377-401, 2020. Disponível em:

https://www.uel.br/revistas/uel/index.php/informacao/article/view/38354. Acesso em: 20 nov. 2020.

MELLO, Mariana Rodrigues Gomes de. Inter-relação entre Ciência da Informação: reflexões histórico-epistemológicas. 2020. 161 f. Dissertação (Mestrado em Ciências Sociais) - Universidade Estadual Paulista, Faculdade de Filosofia e Ciências, Marília, 2020.

MERTON, Robert. The Matthew Effect in Science: The reward and communication systems of science are considered. Science, v. 159, n. 3810, p. 56-63, 1968. Disponível em:

https://science.sciencemag.org/content/159/3810/56/tab-pdf. Acesso em: 15 nov. 2020.

MISKOLCI, Richard. Teoria Queer: Um aprendizado pelas diferenças. Belo Horizonte: Autêntica, 2012.

MORÁN, Ariel. Margaret Elizabeth Egan y la genealogía de la filosofía de la bibliotecología. InCID: Revista de Ciência da Informação e Documentação, Ribeirão Preto, v. 5, n. 2, p. 71-91, 2014. Disponível em: https://www.revistas.usp.br/incid/article/view/75738. Acesso em: 21 dez. 2020.

NASCIMENTO, Maria Ivonete Gomes; OLIVEIRA, Eliane Braga de. Mulher e gênero na produção científica da Ciência da Informação. In: ENCONTRO NACIONAL DE PESQUISA E PÓS-GRADUAÇÃO EM CIÊNCIA DA INFORMAÇÃO (ENANCIB), 20., 2019, Florianópolis. Anais [...]. Florianópolis: UFSC, UDESC, ANCIB, 2019. Disponível em: https://conferencias.ufsc.br/index.php/enancib/2019/paper/view/499/512. Acesso em: 20 nov. 2020.

PELÚCIO, Larissa. Olhares plurais para o cotidiano - gênero, sexualidade e mídia. São Paulo: Cultura Acadêmica, 2012.

PINHEIRO, Lena Vânia Ribeiro. Pesquisadores da Grã-Bretanha pioneiros na história da Ciência da Informação. In: ENCONTRO NACIONAL DE PESQUISA E PÓS-GRADUAÇÃO EM CIÊNCIA DA INFORMAÇÃO (ENANCIB), 14., 2013, Florianópolis. Anais [...]. Florianópolis: UFSC, UDESC, ANCIB, 2013.

Disponível em: https://ridi.ibict.br/bitstream/123456789/469/1/Lena.pdf. Acesso em: 18 nov. 2020.

PRECIADO, Paul Beatriz. Manifesto Contrassexual. São Paulo: N-1 edições, 2014. 223 p. 
RENDÓN ROJAS, Miguel Ángel. O objeto de estudo da

Bibliotecologia/Documentação/Ciência da Informação: construído, complexo, polivalente e transdisciplinar. In: ENCONTRO NACIONAL DE PESQUISA E PÓS-GRADUAÇÃO EM CIÊNCIA DA INFORMAÇÃO (ENANCIB), 13., 2012, Rio de Janeiro. Anais [...]. Rio de Janeiro: ANCIB, 2012. Disponível em: http://repositorios.questoesemrede.uff.br/repositorios/handle/123456789/1091. Acesso em: 20 nov. 2020.

ROBREDO, Jaime. Da Ciência da Informação revisitada aos sistemas humanos de informação. Brasília: Thesaurus, 2003. 246 p.

RODRIGUES, Iraci Oliveira; FRANCELIN, Marivalde Moacir. A Ciência da Informação pela perspectiva feminista. In: ENCONTRO NACIONAL DE PESQUISA E PÓS-GRADUAÇÃO EM CIÊNCIA DA INFORMAÇÃO (ENANCIB), 20., 2019, Florianópolis. Anais [...]. Florianópolis: UFSC, UDESC, ANCIB, 2019. Disponível em:

https://conferencias.ufsc.br/index.php/enancib/2019/paper/view/827/524. Acesso em: 20 nov. 2020.

SAID, Edward. Cultura e imperialismo. São Paulo: Companhia de Bolso, 2011.

SALDANHA, Gustavo Silva. O "fabuloso" antílope de Suzanne Briet: a análise e a crítica da análise neodocumentalista. In: ENCONTRO NACIONAL DE PESQUISA E PÓS-GRADUAÇÃO EM CIÊNCIA DA INFORMAÇÃO (ENANCIB), 13., 2012, Rio de Janeiro. Anais [...]. Rio de Janeiro: ANCIB, 2012. Disponível em:

http://200.20.0.78/repositorios/bitstream/handle/123456789/1093/SALDANHA.p df?sequence=1. Acesso em: 20 dez. 2020.

SANTOS, Bruno Almeida dos; SILVA, Franciéle Carneiro Garcês da; LUBISCO, Nidia Maria Lienert. A bibliografia do esquecimento: por que silenciamos a produção literária de Carolina Maria de Jesus?. In: ENCONTRO NACIONAL DE PESQUISA E PÓS-GRADUAÇÃO EM CIÊNCIA DA INFORMAÇÃO (ENANCIB), 20., 2019, Florianópolis. Anais [...]. Florianópolis: UFSC, UDESC, ANCIB, 2019. Disponível em:

https://conferencias.ufsc.br/index.php/enancib/2019/paper/view/1181/530. Acesso em: 20 nov. 2020.

SANTOS, Jair Ferreira dos. O que é pós-moderno. Brasília: Brasiliense, 1986.

SILVA, Jonathas Luiz Carvalho. Fundamentos da informação I: perspectivas em Ciência da Informação. São Paulo: ABECIN, 2017. 271 p. Disponível em: https://portal.abecin.org.br/editora/article/view/211/186. Acesso em: 17 nov. 2020.

XAVIER, Mariana; KOBASHI, Nair Yumiko. Estudos sobre mulheres na Ciência da Informação. In: ENCONTRO NACIONAL DE PESQUISA E PÓS-

GRADUAÇÃO EM CIÊNCIA DA INFORMAÇÃO (ENANCIB), 20., 2019, 
Florianópolis. Anais [...]. Florianópolis: UFSC, UDESC, ANCIB, 2019.

Disponível em:

https://conferencias.ufsc.br/index.php/enancib/2019/paper/view/1348/533.

Acesso em: 20 nov. 2020.

\title{
EPISTEMOLOGY AND GENDER: A STUDY OF THE PUBLICATIONS OF THE WORKING GROUP 1 OF ENANCIB
}

\begin{abstract}
Aim: study the publications on gender issues and their correlations in the field of information science in the Encontro Nacional de Pesquisa em Ciência da Informação (ENANCIB) and more specifically in the context of the working group 1 (GT1). Methodology: a literature review of the works by authors and philosophers that address the topic was carried out, as well as of the corpus of ENANCIB proceedings for a period of 10 years (2010-2019). Results: thinking about the epistemological question of IS through the lens of gender studies is doing science as praxis, that is, organizing the possibilities for discussion within the production of content itself. Conclusion: new studies that show historical-epistemological aspects related to gender issues and those theories with which they dialogue are suggested, so that IS can promote a better perception of the area, the construction of a mindset with less prejudices, and the reduction of social exclusion. In other words, the deconstruction of IS as a neoliberal science is necessary to give visibility to all groups that have been excluded since its inception.
\end{abstract}

Descriptors: Epistemology. Gender. ENANCIB. Critical Theory.

\section{EPISTEMOLOGÍA Y GÉNERO: UN ESTUDIO DE LAS PUBLICACIONES DEL GRUPO DE TRABAJO 1 DE ENANCIB}

\section{RESUMEN}

Objetivo: estudiar las publicaciones sobre género y sus correlaciones en el campo de la ciencia de la información en el Encontro Nacional de Pesquisa em Ciência da Informação (ENANCIB) y más específicamente en el contexto del grupo de trabajo 1 (GT1). Metodología: se realizó una revisión de la literatura de trabajos de autores y filósofos que abordan la tema, así como el corpus de actas de ENANCIB durante un período de 10 años (2010-2019). Resultados: pensando en la cuestión epistemológica de la $\mathrm{Cl}$ a través del prisma de los estudios de género es hacer lo científico como praxis, es decir, organizar posibilidades de discusión con la propia producción de contenidos. Conclusión: se sugieren nuevos estudios que muestren aspectos históricoepistemológicos relacionados con las cuestiones de género y las teorías con las que dialogan, para que la $\mathrm{Cl}$ pueda promover una mejor percepción del área, la construcción de una mentalidad con menos prejuicios, y la reducción de la exclusión social, en otras palabras, la deconstrucción de la $\mathrm{Cl}$ como ciencia neoliberal es necesaria para dar 
Fernando Cruz Lopes, Mariana Rodrigues Gomes de Mello, Jonathas Luiz Carvalho Silva, Daniel Martínez-Ávila, Oswaldo Francisco de Almeida Junior Epistemologia e Gênero: um estudo das publicações no grupo de trabalho 1 do ENANCIB

visibilidad a todos los grupos que han sido excluidos desde sus inicios.

Descriptores: Epistemología. Género. ENANCIB. Teoría Crítica.

Recebido em: 08.04.2021

Aceito em: 08.12.2021 